\title{
Clinical profile of patients with hypertensive crisis in a tertiary care hospital in Haryana, India - A retrospective cross-sectional study
}

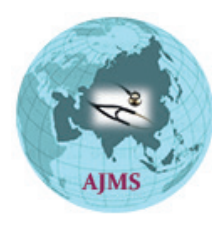

\author{
Navtej Singh ${ }^{1}$, Tarun $^{2}$, Ravinder Pal ${ }^{3}$, Ankit Chamoli ${ }^{4}$ \\ ${ }^{1}$ Professor and Head, ${ }^{2,3}$ Associate Professor, ${ }^{4}$ Postgraduate Resident, Department of General Medicine, Bhagat Phool \\ Singh Government Medical College For Women, Sonepat, Haryana, India
}

Background: A hypertensive crisis may manifest as hypertensive emergency or urgency. Hypertensive emergency is characterized by target organ damage and poses immediate threat to life, a situation not seen in urgency. Aims and Objectives: The aims of the study were as follows: (1) To determine the prevalence of hypertensive crisis classified as emergency, urgency, and pseudocrisis. (2) To assess the various systems (neurological, cardiovascular, and renal) affected in relation to a particular type of hypertensive crisis. Materials and Methods: The retrospective study comprised analysis of medical records of 100 patients of hypertensive crisis admitted to emergency unit of BPS Government Medical College and Hospital for Women, Sonepat, Haryana, India, in the 2 years period from January 2018 to December 2019 and study their prevalence among hospital emergencies and clinical presentation. Results: Total number of clinical emergencies analyzed during this time interval was 6666 . The prevalence of hypertensive crisis accounted to $1.5 \%$ of all the clinical emergencies received. About $66 \%$ presented as hypertensive emergencies, $32 \%$ as hypertensive urgency, and $2 \%$ presented as hypertensive pseudocrisis. Males of the fifth decade of life while females of the sixth decade of life were most affected by hypertensive crisis. Headache (58\%) followed by giddiness (44\%) was the most common clinical presentation in the emergency. About $34 \%$ of patients had associated neurological deficit. Only $16 \%$ of patients had cardiovascular system involvement. Conclusion: Symptoms provided by patients in the emergency department are of paramount importance for the outcome of hypertensive crisis. Severe complication of hypertensive crisis can be prevented if hypertension is timely diagnosed and appropriately managed.

Key words: Hypertension; Hypertensive crisis; Hypertensive emergency; Hypertensive urgency; Prevalence
Access this article online

Website:

http://nepjol.info/index.php/AJMS

DOI: 10.3126/ajms.v13i1.39591

E-ISSN: 2091-0576

P-ISSN: 2467-9100

Copyright (c) 2022 Asian Journal of Medical Sciences

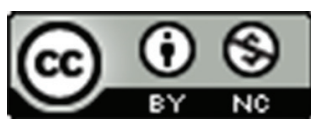

This work is licensed under a Creative Commons Attribution-NonCommercial 4.0 International License.

\section{INTRODUCTION}

HTN is a major health problem around the globe causing 7.5 million deaths $(12.8 \%)$ of the total annual deaths worldwide. The overall burden of the disease is predicted to increase to 1.56 billion adults by $2025 .{ }^{1}$ Among the hypertensive population, about $1-2 \%$ of the patients develop hypertensive crisis. ${ }^{2}$ According to the 2003 Joint National Committee (JNC) on prevention detection, evaluation, and treatment of high blood pressure (JNC7), hypertensive crisis is defined as elevation of systolic blood pressure $>179 \mathrm{mmHg}$ or diastolic blood pressure of $>109$ mmHg., ${ }^{2,3}$ A hypertensive crisis may manifest as hypertensive emergency or urgency. In hypertensive urgency, immediate threat to life and end-organ damage is not seen as compared to hypertensive emergency. This differentiation is important entity in clinical practice as far management is concerned. Immediate lowering of the blood pressure is required to prevent irreversible endorgan damage and mortality in hypertensive emergency. The blood pressure should be reduced in 24-48 h in hypertensive urgency, which decreases morbidity. ${ }^{3}$ 
However, a patient presenting with hypertensive urgency may have a history of previous target or end-organ damage. $^{4}$

If heart is the target organ involved in hypertensive crisis, it may culminate in acute pulmonary edema. Acute renal failure is another manifestation of hypertensive emergency. ${ }^{5}$ Differences in the amount of cardiac output received, total oxygen consumption, and auto-regulatory capacity (i.e., auto-regulatory dependence) may explain some of the differences in the prevalence of individual organ dysfunction. ${ }^{6}$

Although hypertensive emergencies can lead to significant morbidity and potentially fatal target organ damage, only $1-3 \%$ of patients with hypertension will have a hypertensive emergency during their lifetime. ${ }^{7}$

To describe the pathophysiology during a hypertensive emergency, acute elevation in blood pressure overwhelms the autoregulation of the endothelial control of vascular tone, leading to mechanical vascular wall stress with subsequent endothelial damage and vascular permeability. ${ }^{8}$ This permeability leads to the leakage of plasma into the vascular wall, resulting in activation of platelets, initiation of the coagulation cascade, deposition of fibrin, and recruitment of inflammatory mediators. ${ }^{\text {? }}$ This inappropriate vasoconstriction and microvascular thrombosis lead to hypoperfusion and end-organ ischemia with subsequent target organ dysfunction. The activation of renin-angiotensin system can further accentuate vasoconstriction and ischemia.

Pseudocrisis neither has evidence of target organ lesions nor immediate threat to life but very higher blood pressure levels. This is usually caused by emotional uncomfortable event or painful stimuli in patients with essential hypertension. ${ }^{10}$

\section{Aims and objectives}

The aims of the study were as follows:

1. To determine the prevalence of hypertensive crisis classified as emergency, urgency, and pseudocrisis.

2. To assess the various systems (neurological, cardiovascular, and renal) affected in relation to a particular type of hypertensive crisis.

\section{MATERIALS AND METHODS}

This is a retrospective study conducted by analyzing medical records of patients admitted to medical emergency unit of BPS Government Medical College and Hospital for Women, Sonepat, Haryana, in 2 years from January 2017 to December 2018.
All the patients presenting with hypertensive crisis in said interval of time, fulfilling inclusion and exclusion criteria were included in the study.

One hundred patients with hypertensive crisis were included in the study. Baseline demographic data such as age and sex were recorded for each patient.

\section{Inclusion criteria}

The following criteria were included in the study:

1. Adult patients of both sexes above 18 years.

2. Systolic blood pressure $>180 \mathrm{mmHg} /$ diastolic blood pressure of $>120 \mathrm{mmHg}$ with or without history of hypertension.

\section{Exclusion criteria}

1. Pregnant females were excluded from the study (because hypertension in pregnancy is a completely different entity with entirely different pathophysiology and management).

All cases in which elevated blood pressure was associated with target organ lesions were classified as hypertensive emergencies with their respective codes according to International Classification of Diseases (ICD), Tenth Revision, Clinical Modification ${ }^{11}$ codes as given in Table 1. Patients lacking target organ damage were categorized as hypertensive urgencies (I16.0).

These conditions were diagnosed on basis of clinical history, detailed physical examination, and diagnostic tests at the time of admission. Blood pressure recordings (mercury sphygmomanometer) were noted. Biochemical tests (blood sugar, serum electrolytes, renal function tests, and lipid profile) and electrocardiogram were analyzed.

\begin{tabular}{|c|c|}
\hline Diagnosis & ICD \\
\hline Hypertensive crisis & I16 \\
\hline Hypertensive emergency & I16.1 \\
\hline Essential hypertension & 110 \\
\hline Hypertensive urgency & I16.0 \\
\hline Left ventricular failure & 150.1 \\
\hline Congestive heart failure & I11.0 \\
\hline $\begin{array}{l}\text { Hypertensive heart and chronic kidney disease } \\
\text { without heart failure and Stage } 1 \text { through Stage } \\
4 \text { chronic kidney disease, or unspecified chronic } \\
\text { kidney disease }\end{array}$ & 113.10 \\
\hline Ischemic heart disease & I25.5 \\
\hline Acute myocardial infarction & I21/I22/I23 \\
\hline Chronic kidney disease/renovascular & N18/N17 \\
\hline Dilated cardiomyopathy & 142 \\
\hline Hypertensive encephalopathy & 167.4 \\
\hline Cerebral infarction/stroke & 163 \\
\hline
\end{tabular}


Fundus examination categorized as Grades I, II, III, and IV. Radiological tests included chest X-ray, ultrasound abdomen, renal Doppler, and computerized tomography head plain/contrast aiding diagnosis wherever necessary.

\section{Statistical analysis}

Results were expressed as mean and standard deviation. Data were tabulated presented as numbers and percentages. $\mathrm{P}<0.005$ was considered statistically significant.

\section{RESULTS}

Of the total number of patients retrospectively evaluated in the emergency and medicine department, during a 1 year period from January to December 2019, the prevalence of hypertensive crisis (ICD I16) was 100 cases which accounted to $1.5 \%$ of all the clinical emergencies received $(\mathrm{n}=6666)$. Hypertensive emergencies (ICD I16.1) were 66 cases $(67.34 \%)$, and rest 32 cases $(32.65 \%)$ were of hypertensive urgencies (ICD I16.0) as shown in Figure 1. Two patients with essential hypertension (ICD I10) presenting as pseudo crisis due to emotional cause were also observed.

Most of the patients were male of the fifth decade of life with a mean age of 57.13 , while females of the sixth decade were most affected with mean age of females which was 62.57 .

Out of the total 98 cases of hypertensive crisis excluding pseudocrisis, maximum number of 44 cases (44.89\%) were observed in 61-70 years age group followed by $51-60$ years age groups. Least number of patients of hypertensive crisis were found in above 81 years (2.04\%) due low number of patients surviving in India of this age group (Table 2).

Females were less affected by hypertensive crisis as compared to males with a male-to-female ratio of 3:2. This is also evident in each age group except a higher incidence being observed in 61-70 years age group with more cases of females as compared to males.

Out of the total 66 patients of hypertensive emergency, 28 were female and 38 males. Age range of 30-76 years in males and 35-75 years in females was recorded. Patients with hypertensive urgencies were older with an age range of 40-74 in males, 55-80 in females. There were 22 males and 12 females' cases of hypertensive urgency (Figure 2).

Hypertensive emergencies were observed more in female $(71.42 \%)$ as compared to males $(25 \%)$ in $61-70$ years age group, whereas urgency was observed in $54 \%$ of males and $33.3 \%$ of females of this age group as shown in Table 2.

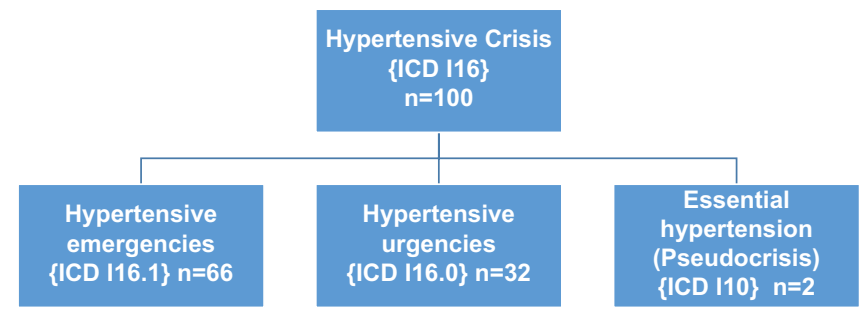

Figure 1: Distribution of patients of hypertensive crisis as per International Classification of Diseases, Tenth Revision, Clinical Modification $^{9}$

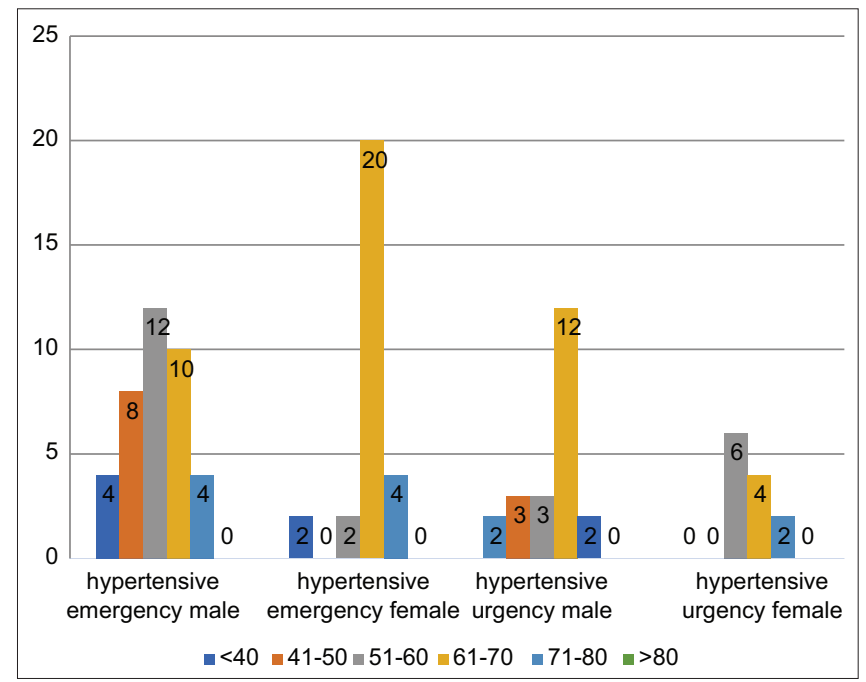

Figure 2: Distribution of hypertensive emergency and urgency according to age group and sex

\begin{tabular}{|c|c|c|c|}
\hline Age group & $\begin{array}{l}\text { Number of cases in } \\
\text { each group }(n=98)\end{array}$ & $\begin{array}{l}\text { Males } \\
(n=58)\end{array}$ & $\begin{array}{c}\text { Females } \\
(n=40)\end{array}$ \\
\hline$<40$ years & 6 & 4 & 2 \\
\hline $41-50$ years & 12 & 12 & 0 \\
\hline $51-60$ years & 22 & 14 & 8 \\
\hline $61-70$ years & 44 & 20 & 24 \\
\hline $71-80$ & 12 & 6 & 6 \\
\hline $\begin{array}{l}81 \text { and above } \\
\text { Mean and SD }\end{array}$ & 2 & 2 & 0 \\
\hline
\end{tabular}

The next common age group involved was the 51-60 years, 14 cases of hypertensive emergencies and 10 cases of urgency. Males (31.5\%) outnumbered females $(7 \%)$ in an emergency presentation.

Equal presentation of males and females was observed in both hypertensive urgency and emergency in the $71-80$ years age group. The number of cases was in the ratio of 2:1 in emergency and urgency presentation. Similar presentation of this ratio of emergency and urgency is seen in 41-50 years age group. However, no females presented as hypertensive emergency or urgency in this age group. 
The $<40$ years age group had four patients of emergency and only two patients of urgency, male-to-female ratio was 2:1 in emergency presentation. No female presented with an urgency profile.

The most common clinical presentation of patients of hypertensive crisis was headache observed in 58\% of patients followed by giddiness $44 \%$ in patients of hypertensive crisis. Neurological deficit was witnessed in $34 \%$ and vomiting in $28 \%$ of patients. The respiratory symptoms were the most common complaint after CNS involvement as evident by dyspnea observed in $40 \%$ and chest pain in $38 \%$ of the patients. Facial puffiness was observed in only $12 \%$ of patients with hypertensive crisis (Table 3).

The presentation of cardiovascular involvement in hypertensive crisis patients varied. The most common involvement suffered by the patients was left ventricular hypertrophy (LVH) observed in 16\%. LVH associated with ischemic heart disease and acute left ventricular failure was seen in only $4 \%$ of the patients, respectively. About $2 \%$ of the cases had dilated cardiomyopathy. LVH was the prominent cardiovascular involvement in both patients with hypertensive urgency $(18.7 \%)$ and hypertensive emergency in $(15.1 \%)$ patients. Acute left ventricular failure was the complication seen in hypertensive urgency in $6.2 \%$ of cases but in 3\% of the cases of hypertensive emergency (Table 4).

Transient ischemic attack and hypertensive encephalopathy were diagnosed clinically in $2 \%$ of the patients of hypertensive crisis with CNS involvement. Cerebral infarction was diagnosed with help of CT scan or MRI accounted to presentation in $16 \%$; and another $16 \%$ of patients had both cerebral infarctions coexisting with hypertensive encephalopathy. CNS complications due to uncontrolled blood pressure accounted to $36.7 \%$ of all hypertensive crises (Table 5).

About 25\% of patients had renal complication of hypertension. Renal size of kidney was decreases in four patients with hypertensive crisis. About $12 \%$ suffered due to renovascular abnormalities with higher frequency as an urgency presentation at $9.3 \%$ and just $4.5 \%$ as an emergency. Chronic kidney disease occurred in $8.2 \%$ and medical renal parenchymal disease in $4 \%$ of hypertensive emergencies only (Table 6). Forty patients had urine positive for proteins with $14 \%$ showing traces, $14 \%$ had protein $1+$, and $6 \%$ had protein $2+$ and $3+$, respectively.

Blood urea was elevated in $24 \%$ of the patients above $40 \mathrm{mg} / \mathrm{dl}, 10$ patients had elevated levels of serum creatinine above $1.2 \mathrm{mg} / \mathrm{dl}$.

Twenty-four out of 100 patients of hypertensive emergencies had evidence of retinal damage on fundus examination. Fourteen patients had Grade I (\%), six patients had Grade II, while four patients had Grade III $(\%)$ retinopathy (Figure 3).

The most common cardiovascular abnormality detected on ECG in patients of hypertensive crisis patients was LVH followed by inferior wall ischemia (Table 7).

\begin{tabular}{lcccc} 
Table 3: Frequency of signs and symptoms found in hypertensive crisis \\
\hline Signs and symptoms & $\begin{array}{c}\text { Number of patients with } \\
\text { hypertensive crisis (\%) } \\
(\mathbf{n = 1 0 0 )}\end{array}$ & $\begin{array}{c}\text { Number of patients } \\
\text { with hypertensive } \\
\text { emergency (\%) } \\
(\mathbf{n = 6 6 )}\end{array}$ & $\begin{array}{c}\text { Number of patients } \\
\text { with hypertensive } \\
\text { urgency (\%) } \\
(\mathbf{n = 3 2 )}\end{array}$ & $\begin{array}{c}\text { Number of patients } \\
\text { with essential } \\
\text { hypertension }(\%) \\
(\mathbf{n = 2})\end{array}$ \\
\hline Dyspnea & $40(40)$ & $26(39.4)$ & $12(37.5)$ & $2(100)$ \\
Neurological deficit & $34(34)$ & $32(48.5)$ & $2(6.25)$ & - \\
Headache & $58(58)$ & $32(48.5)$ & $24(75)$ & $2(100)$ \\
Chest pain & $38(38)$ & $20(30.3)$ & $16(50)$ & $2(100)$ \\
Chest heaviness & $16(16)$ & - & $16(50)$ & - \\
Giddiness & $44(44)$ & $32(48.5)$ & $10(31.2)$ & $2(100)$ \\
Vomiting & $28(28)$ & $18(27.3)$ & $8(25)$ & $2(100)$ \\
Facial puffiness & $12(12)$ & $10(15.2)$ & $2(6.25)$ & - \\
\hline
\end{tabular}

\begin{tabular}{lccc} 
Table 4: Cardiovascular system involvement & \\
\hline Nature of involvement & $\begin{array}{c}\text { Number of patients of } \\
\text { hypertensive crisis }(\%) \\
(\mathbf{n = 1 0 0 )}\end{array}$ & $\begin{array}{c}\text { Number of patients with } \\
\text { hypertensive emergency (\%) } \\
(\mathbf{n}=66)\end{array}$ & $\begin{array}{c}\text { Number of patients with } \\
\text { hypertensive urgency (\%) } \\
(\mathbf{n}=\mathbf{3 2})\end{array}$ \\
\hline LVH & $16(16)$ & $10(15.1)$ & $6(18.75)$ \\
LVH+lschemic heart disease & $4(4)$ & $4(6)$ & - \\
Acute left ventricular failure & $4(4)$ & $2(3)$ & $2(6.2)$ \\
Dilated cardiomyopathy & $2(2)$ & $2(3)$ & - \\
\hline LVH: Left ventricular hypertrophy & & &
\end{tabular}


Diabetes was a statistically significant risk factor for the development of hypertensive crisis as evident in 57 out of 100 patients. The diagnosis of diabetes mellitus was more frequent in patients with emergencies than those of urgency. Smoking was equally seen as a risk factor observed in 30 out of 100 patients.

\section{DISCUSSION}

Hypertension-mediated diseases are on progression in India and constantly affecting the health of its population until not intervened India will land up into cardiovascular catastrophe. Few data exist on complications of hypertension in rural set up in Haryana, therefore, study aimed at estimating the prevalence of hypertensive crisis.

In the present study, hypertensive crisis accounted to $1.5 \%$ of all emergencies similar to study conducted

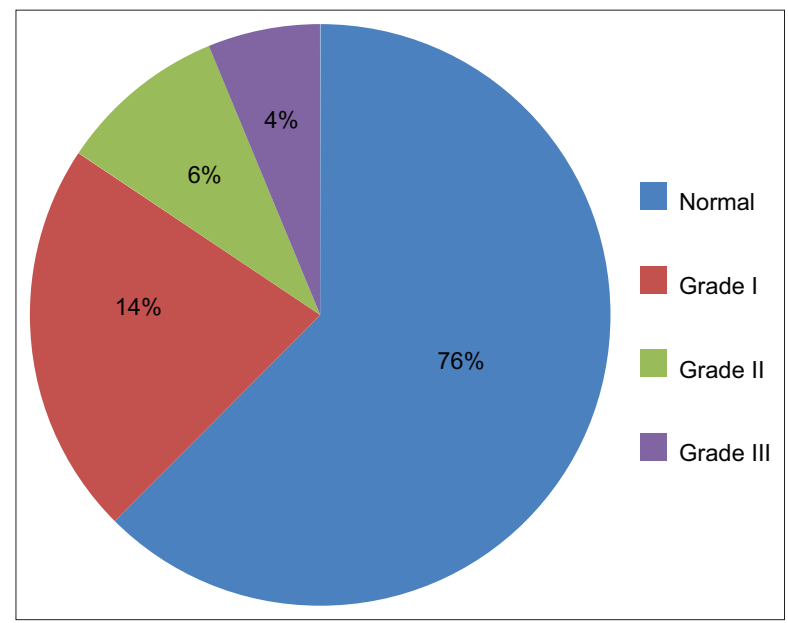

Figure 3: Retinopathy in hypertensive crisis

\section{Table 5: Central nervous system involvement}

\begin{tabular}{lcc}
\hline Nature of involvement & $\begin{array}{c}\text { Number of } \\
\text { patients }(\mathbf{n = 1 0 0 )}\end{array}$ & Percentage \\
\hline Cerebral infarction & 16 & 16 \\
Cerebral & 16 & 16 \\
infarction+Hypertensive & & \\
encephalopathy & 2 & 2 \\
Transient ischemic attack & 2 & 2 \\
Hypertensive & & \\
encephalopathy & & \\
\hline
\end{tabular}

in Brazil by Martin et al., in $2004^{10}(1.7 \%)$ and $1.22 \%$ in Solapur, India, by Dhadke et al., 2017. ${ }^{12}$ These data differ from an Italian study by Zampaglione et al., 1996, ${ }^{13}$ in which the prevalence of hypertensive crisis was 3\% of all medical emergencies. The higher prevalence rate could be due to inclusion of patients of hypertensive pseudocrisis as explained by Nobre et al., 2002, ${ }^{14}$ who observed $64.5 \%$ of hypertensive pseudocrisis patients being inappropriately treated in emergency as hypertensive crisis only reassessment and medical counseling is required. A recent study conducted by de Souza Filho et al., 2019, ${ }^{15}$ in Brazil has observed a prevalence of just $0.6 \%$. The possible explanation is that ours is a retrospective study and demographic data obtained through review of medical records lead to lower accuracy than a prospective study. Second, study comprises cases from single institution.

It was found, prevalence of hypertensive emergencies $(67.32 \%)$ higher than urgencies opposite to studies in Brazil where only $39.6 \%$ in $2004^{10}$ and $25.3 \%{ }^{15}$ of cases in 2019 were emergencies. Hypertensive urgencies had a higher prevalence in their studies $60.4 \%$ in $2004^{10}$ and rise to $74.7 \%$ in $2019 .{ }^{15}$ This can be explained possibly because of the heightened awareness, recognition, and subsequent diagnosis of hypertensive emergency. Hospitalizations because of hypertensive emergencies have increased since 2000 (Deshmukh et al., 2011). ${ }^{7}$ Diabetes was a statistically significant risk factor for the development of hypertensive emergencies as observed in $55 \%$ of the individuals in the present study. Presence of only $26 \%$ of diabetic individuals was reported in Brazil by Martin et al., 2004. ${ }^{10}$

Low prevalence of hypertensive pseudocrisis $4 \%$ was observed by de Souza Filho et al., 2019, ${ }^{15}$ similar to the present study of just $2 \%$.

Most of the patients were males of the fifth decade of life with a mean age of 57.13 , while females of the sixth decade were most affected with mean age of females which was 62.57 not differing from other studies.

The patients with hypertensive emergencies were submitted to a higher proportion of laboratory tests compared to those of urgencies.

\begin{tabular}{lccc} 
Table 6: Renal involvement & $\begin{array}{c}\text { Number of patients with } \\
\text { hypertensive crisis (\%) } \\
(\mathbf{n}=\mathbf{1 0 0})\end{array}$ & $\begin{array}{c}\text { Number of patients with } \\
\text { hypertensive emergency (\%) } \\
(\mathbf{n}=66)\end{array}$ & $\begin{array}{c}\text { Number of patients with } \\
\text { hypertensive urgency }(\%) \\
(\mathbf{n}=\mathbf{3 2})\end{array}$ \\
\hline USG abnormality & $12(12)$ & $9(13.6)$ & $3(9.3)$ \\
Renovascular & $8(8)$ & 8 & - \\
Chronic kidney disease & $4(4)$ & 4 & - \\
Medical renal parenchymal disease & $76(76)$ & - & - \\
Normal & & - & \\
\hline
\end{tabular}




\begin{tabular}{|c|c|c|}
\hline Finding & ECG & $\mathrm{ECHO}$ \\
\hline LVH & 18 & 4 \\
\hline Atrial fibrillation & 2 & - \\
\hline Inferior wall ischemia & 16 & - \\
\hline Right bundle branch block & 2 & - \\
\hline Inferior wall myocardial infarction & 2 & - \\
\hline $\begin{array}{l}\text { Non-ST-segment elevation } \\
\text { myocardial infarction }\end{array}$ & 2 & - \\
\hline
\end{tabular}

The importance of this study is based on the clinical profile or symptoms on presentation by the study population, which made classification of hypertensive crisis possible and identification of its relation with symptoms and signs for each type. Headache was the most frequent symptom in the present study (58.2\%) associated with hypertensive crisis similar to other studies. ${ }^{10,12,15}$ Besides, in the present study, headache presented a higher frequency among patients with hypertensive urgency $(75 \%)$ than in emergency (48.5\%) similar to de Souza Filho et al., 2019. ${ }^{15}$ Increased cerebral blood flow consequent to vasodilation due to failure of brain self-regulating mechanism is closely linked to headache.

Neurological deficit and giddiness (48.5\%), respectively, were most frequent symptoms of emergency followed by dyspnea (39.4\%) and chest pain (30.3\%) suggesting target organ damage. Similar findings in Brazilian literature with heightened neurological problems (48.1\%) and dyspnea $(27.2 \%)$ have been observed. ${ }^{15}$ Facial puffiness was reported by $15.2 \%$ of patients of hypertensive emergencies again indicative of end-organ damage. Heaviness in the chest $(50 \%)$ followed by dyspnea $(37.5 \%)$ was observed in patients of urgency. Vomiting was observed in the in both the categories equally (25\%). Giddiness vomiting and headache were seen in patients with pseudocrisis indicative of emotional problems. The diagnosis of diabetes mellitus was more frequent in patients with hypertensive emergencies than those of urgency which differs from Brazilian population studied by de Souza Filho et al. (2019). ${ }^{15}$

Patient empowerment using information technology (mobile phone apps and understandable educational tools) should be activated. None of these avenues can be traversed without professional education in the arena of non-communicable disease prevention. Over decades, the country has been witnessing a steady rise in BP levels, cholesterol levels, glucose levels, body weight, sedentary lifestyle, and unhealthy nutrition which calls for multidimensional comprehensive preventive measures. Lifestyle changes have to be enforced to prevent hypertensive crisis. National policies and objectives are often discussed, cited, and promoted but not implemented increasing its sequelae as discussed above. To meet the objective of decreasing the cardiovascular disease mortality by $25 \%$ by 2025 , the prevalence of hypertension in India has to be reduced by $25 \%$ and secondary prevention by $50 \%$. To achieve and maintain the recommended therapeutic goals of blood pressure control, practicing doctor should monitor patient closely after initiating the treatment. India has done it in past to contain the communicable diseases and can do same for non-communicable diseases as well.

\section{Limitation of the study}

The limitation of the current study is that retrospective study design involving the collection of demographic data obtained through review of medical records has led to lower accuracy than a prospective study. Second, study comprises sample taken from single institution.

\section{CONCLUSION}

The increasing prevalence of the hypertension calls for better prevention and management of the disease with special focus on emergency presentations. The outcome of the hypertensive crisis depends largely on the presenting symptoms of the patients in the emergency department. A timely diagnosis and its appropriate management can lead to prevention of severe complications and fatal outcomes, thereby reducing the overall morbidity and mortality due to hypertension.

\section{REFERENCES}

1. Singh S, Shankar R and Singh GP. Prevalence and associated risk factors of hypertension: A cross-sectional study in Urban Varanasi. Int J Hypertens. 2017;2017:5491838.

http://doi.org/10.1155/2017/5491838

2. Chobanian AV, Bakris GL, Black HR, Cushman WC, Green LA, Izzo JL, et al. The seventh report of the joint national committee on prevention, detection, evaluation, and treatment of high blood pressure: The JNC 7 report. JAMA. 2003;289(19):2560-2572. http://doi.org/10.1001/jama.289.19.2560

3. Muiesan ML, Salvetti M, Amadoro V, di Somma S, Perlini S, Semplicini $A$, et al. An update on hypertensive emergencies and urgencies. J Cardiovasc Med Hagerstown Md. 2015;16(5):372-382. http://doi.org/10.2459/JCM.0000000000000223

4. Papadopoulos DP, Mourouzis I, Thomopoulos C, Makris T and Papademetriou V. Hypertension crisis. Blood Press. 2010;19(6):328-336. http://doi.org/10.3109/08037051.2010.488052

5. Varounis C, Katsi V, Nihoyannopoulos P, Lekakis J and Tousoulis D. Cardiovascular hypertensive crisis: Recent evidence and review of the literature. Front Cardiovasc Med. 2016;3:51. 
http://doi.org/10.3389/fcvm.2016.00051

6. Myers JD and Hickam JB. An estimation of the hepatic blood flow and splanchnic oxygen consumption in heart failure. J Clin Invest. 1948;27(5):620-627.

http://doi.org/10.1172/JCl102008

7. Deshmukh A, Kumar G, Kumar N, Nanchal R, Gobal F, Sakhuja A, et al. Effect of Joint national committee VII report on hospitalizations for hypertensive emergencies in the United States. Am J Cardiol. 2011;108(9):1277-1282.

http://doi.org/10.1016/j.amjcard.2011.06.046

8. Vaughan CJ and Delanty N. Hypertensive emergencies. Lancet Lond Engl. 2000;356(9227):411-417.

http://doi.org/10.1016/S0140-6736(00)02539-3

9. Derhaschnig U, Testori C, Riedmueller E, Aschauer S, Wolzt M and Jilma B. Hypertensive emergencies are associated with elevated markers of inflammation, coagulation, platelet activation and fibrinolysis. J Hum Hypertens. 2013;27(6):368-373.

http://doi.org/10.1038/jhh.2012.53

10. Martin JF, Higashiama E, Garcia E, Luizon MR and Cipullo JP. Hypertensive crisis profile. Prevalence and clinical presentation. Arq Bras Cardiol. 2004;83(2):131-136; 125-130. http://doi.org/10.1590/s0066-782x2004001400004

11. 2020 ICD-10-CM CMS. Available from: https://www.cms.gov/ Medicare/Coding/ICD10/2020-ICD-10-CM [Last accessed on 2021 Nov 04].

12. Dhadke SV, Dhadke VN and Batra DS. Clinical profile of hypertensive emergencies in an intensive care unit. J Assoc Physicians India. 2017;65(5):18-22.

13. Zampaglione B, Pascale $\mathrm{C}$, Marchisio $\mathrm{M}$, and Cavallo-Perin $\mathrm{P}$. Hypertensive urgencies and emergencies. Prevalence and clinical presentation. Hypertension. 1996;27(1):144-147. http://doi.org/10.1161/01.hyp.27.1.144

14. Nobre F, Chauchar F, Viana JM, Pereira GJ and da Costa Lima NK. Evaluation of the medical care of patients with hypertension in an emergency department and in ambulatory hypertension unit. Arq Bras Cardiol. 2002;78(2):159-161. http://doi.org/10.1590/s0066-782x2002000200003

15. de Souza Filho ZA, Ferreira AA, Santos BD and Pierin AM. Hypertension prevalence among indigenous populations in Brazil: A systematic review with meta-analysis. Rev Esc Enferm USP. 2015;49(6):1016-1026.

http://doi.org/10.1590/S0080-623420150000600019

\section{Authors' Contributions:}

NS- Concept and design of the study, statistical analysis and interpretation, reviewed the literature, and prepared first draft of manuscript; T- Concept, coordination, statistical analysis, and interpretation; RP- Reviewed the literature and manuscript preparation; AC- Coordination, statistical analysis and interpretation, and revision of the manuscript.

\section{Work attributed to:}

Bhagat Phool Singh Government Medical College for Women, Sonepat - 131 301, Haryana, India.

\section{ORCID ID:}

Dr. Navtej Singh - (1) https://orcid.org/0000-0002-0348-6822

Dr. Tarun - (D https://orcid.org/0000-0003-1201-5990

Dr. Ravinder Pal - (1) https://orcid.org/0000-0001-9691-156X

Dr. Ankit Chamoli - io https://orcid.org/0000-0002-4837-0962

Source of Funding: None, Conflicts of Interest: None. 